\title{
Raíces y ramas al viento: experiencias colombianas de migración y prácticas de información ${ }^{*}$
}

\author{
Roots and branches to the wind: Colombian migration experiences \\ and information practices
}

Raizes e galhos ao vento: experiências migratórias colombianas e práticas de informação

\footnotetext{
* Profesor Asociado, Escuela Información de la Universidad de Washington, especializado en temas de usos comunitarios de las tecnologías de información, bibliotecas públicas y evaluación de impactos. Correo electrónico:rgomez@uw.edu

** Artículo que presenta la segunda parte del resultado de investigación Proyecto Fotohistorias: fotografía participativa y experiencias de migración, 2013-2016, con financiación parcial de Royalty Research Fund de Universidad de Washington. La primera parte de esta investigación aparece en GÓMEZ, R. (2016). Vulnerabilidad y prácticas de información: experiencias de migrantes latinos (indocumentados) en EE.UU. Revista CS, no. 20, pp. 93-121. Cali, Colombia: Facultad de Derecho y Ciencias Sociales, Universidad Icesi. Artículo de investigación recibido el 23/05/2016 y aceptado el 19/08/2016.
} 


\section{Cómo citar}

GómEZ, R. (2017). Raíces y ramas al viento: experiencias colombianas de migración y prácticas de información. Revista CS, 22, pp. 33-53. Cali, Colombia. Facultad de Derecho y Ciencias Sociales, Universidad Icesi. 


\section{Resumen}

Este artículo presenta los hallazgos en Colombia de un estudio más grande que explora las prácticas de información (búsqueda, uso y distribución de la información) de los migrantes latinos, en particular de aquellos que están indocumentados, en tres contextos distintos: en la frontera entre México y EE.UU., en Seattle, Washington y en Cali, Colombia. En el contexto colombiano las experiencias de migración de los participantes oscilan entre echar raíces y alzar vuelo, entre quedarse e irse, entre aquí y allá. Muchas de estas experiencias buscan construir futuro para quedarse, para no tener que migrar, las cuales contrastan con las experiencias de vulnerabilidad y transitoriedad en la frontera entre México y EE. UU., y en Seattle, Washington, analizadas en Gómez (2016). A través de la fotografía participativa y entrevistas no estructuradas, exploramos las vivencias y las prácticas de información de comunidades marginadas, y las relacionamos con cómo vivencian la transitoriedad a lo largo de las distintas etapas de la experiencia migratoria. También discutimos cómo las etapas de la migración pueden no ser suficientes para dar cuenta de los constantes cambios e iteraciones en las experiencias de los migrantes que estudiamos.

PALABRAS CLAVE:

Migrantes latinos | Indocumentados | Migración | Fotografía participativa | Prácticas de información

This article presents the findings in Colombia of a larger study that explores the information practices (search, use and distribution of information) of Latino migrants, particularly those who are undocumented, in three different contexts: on the border between Mexico and EE.UU., in Seattle, Washington and in Cali, Colombia. In the Colombian context, participants' migration experiences oscillate between taking root and flying, between staying and leaving, between here and there. Many of these experiences seek to build a future to stay, not to migrate, which contrast with the experiences of vulnerability and transience on the border between Mexico and the USA. And in Seattle, Washington, analyzed in a separate article, in this same volume. Through participatory photography and unstructured interviews, we explore the experiences and information practices of marginalized communities, and relate 
them to how they experience transience throughout the different stages of the migratory experience. We also discussed how the stages of migration may not be sufficient to account for the constant changes and iterations in the experiences of the migrants we studied.

\section{KEYWORDS:}

Latino migrants | Undocumented | Migration | Participatory photography | Information practices

Este artigo apresenta os resultados na Colômbia de um estudo maior que explora práticas de informação (pesquisa, uso e distribuição da informação) dos migrantes latinos, particularmente aqueles que são indocumentados, em três contextos diferentes: na fronteira entre México e EE.UU., em Seattle, Washington e em Cali, na Colômbia. No contexto colombiano, as experiências de migração dos participantes oscilam entre «o galho e o vôo», entre ficar e sair, entre aqui e lá. Muitas dessas experiências procuram construir um futuro para permanecer, não para migrar, o que contrasta com as experiências de vulnerabilidade e transitoriedade na fronteira entre o México e os EUA. e em Seattle, Washington, analisadas em Gómez (2016). Através da fotografia participativa e entrevistas não estruturadas, exploramos as experiências e as práticas de informação das comunidades marginalizadas e as relacionamos com a forma como vivenciam a transitoriedade ao longo das diferentes etapas da experiência migratória. Também discutimos como as etapas da migração podem não ser suficientes para explicar as constantes mudanças e iterações nas experiências dos migrantes que estudamos.

\section{PALAVRAS CHAVES:}

Migrantes latinos | Indocumentado | Migração | Fotografia participativa |

Práticas de informação 


\section{Introducción}

Los migrantes dejan su lugar de origen para establecerse en un nuevo lugar. Independientemente de si migran voluntariamente o no, se embarcan en un viaje que toca las fibras más profundas de la experiencia humana: ¿De dónde venimos? ¿Para dónde vamos? ¿Quiénes somos? Estas preguntas, dramáticamente puestas sobre el lienzo por Paul Gaugin en su obra maestra de 1897, se han vuelto progresivamente más importantes en el siglo transcurrido desde que lo pintó: el siglo de la migración. En la primera página de su libro sobre migración, Thomas Nail declaró que «(e)l siglo XXI será el siglo del migrante» (2015:1), para luego añadir que «todos nos estamos convirtiendo en migrantes». Más adelante, arguye que «la mayoría de las personas se ubican en el espectro migratorio, entre el polo de la "inconveniencia" (turistas, académicos viajando y ejecutivos) y el polo de la "incapacidad" (refugiados y migrantes, trabajadores indocumentados)» (Nail, 2015:1-2). Ya sea que estén sometidos a inconvenientes menores, o sean excluidos o rechazados del todo, todos los migrantes buscan, usan y comparten información como parte fundamental del proceso a través del cual le dan sentido a su experiencia. Las preguntas existenciales que se planteó Gaugin pueden ser contestadas de manera diferente por personas que se ubican en puntos distintos del espectro migratorio descrito por Nail, toda vez que desarrollan prácticas diferentes para buscar, usar y compartir información. Las prácticas de información (information practices) y los comportamientos de información (information behaviors) son temas de estudio frecuentes en la ciencia de la información. Las prácticas de información están frecuentemente clasificadas en tres conjuntos diferenciados de actividades: la búsqueda de la información, su uso y su distribución (Savolainen, 2008). De manera análoga, el estudio de los comportamientos de información se «enfoca en las necesidades de información que tienen las personas, o en otras palabras, cómo buscan, administran, dan y usan información, tanto de manera activa como pasiva, en los roles que asumen en su vida cotidiana» (Fisher y Julien, 2009). Adoptamos el enfoque de prácticas de información en lugar del de comportamientos de información, porque el primero permite una aproximación más constructivista (en vez de psicológica) para entender la experiencia de los usuarios, que son, en nuestro caso, los migrantes.

Presentamos en seguida la metodología de investigación con fotografía participativa y los diferentes contextos para el estudio en la región de Cali, Colombia. En seguida presentamos los principales hallazgos, organizados por lugar, comenzando por la comunidad afro-descendiente de Bahía Málaga, siguiendo con la comunidad indígena de Buenavista, y terminando con la comunidad obrera de Siloé. Para terminar, presentamos las conclusiones principales de este estudio. 


\section{Métodos: Fotohistorias y fotografía participativa}

Fotohistorias es un método que recurre a la fotografía participativa y a las entrevistas en persona con migrantes para obtener una comprensión más íntima de la experiencia de los migrantes y revelar la complejidad, riqueza y diversidad de sus raíces, vivencias y aspiraciones (Gómez y Vannini, 2015; Yefimova et al., 2015). El proceso de la fotografía participativa incluye invitar a los participantes a que participen, que ellos tomen fotos nuevas o traigan sus propias fotografías y finalmente llevar a cabo una entrevista semi estructurada y en tono de conversación para hablar de las fotos. Este método permite una comprensión más profunda de las experiencias de los entrevistados y sus percepciones sobre el objeto de estudio.

La metodología de Fotohistorias tiene cuatro fases principales: (1) colaboración con organizaciones locales: trabajar con organizaciones locales en cada ubicación de la investigación ayuda a construir la confianza necesaria para invitar a voluntarios a participar, y ofrece un canal para socializar los resultados de la investigación con un grupo que puede luego usarlos para generar conciencia sobre la temática, mejorar sus programas o recaudar fondos. (2) Generación de imágenes: los participantes pueden o tomar en préstamo una cámara digital básica o usar la propia (muchos de ellos tienen teléfonos inteligentes, «smart phones»), por una duración preestablecida (entre un día y una semana, dependiendo de las circunstancias). Se les invita a que tomen y compartan fotos que representan sus vivencias y su cotidianidad. Encontramos que era útil compartirles, además del consentimiento informado para participar, otros tres documentos: instrucciones básicas para el uso de la cámara (en caso de ser necesario), lineamientos éticos para la toma de las fotografías (v.gr. pedir permiso, no meterse ni meter a otros en problemas) e ideas sobre cuáles fotos tomar (no como lista exhaustiva, sino como ejemplos de las posibilidades: un «selfie», lugares que frecuenta, cosas que le gusta comer, etc.). (3) Conversación sobre las fotos: nos reunimos con los participantes después del tiempo acordado para la toma de las fotos y juntos miramos las fotos que han traído y que han elegido para hablar de ellas (la meta es entre 7 y 10 imágenes). Las fotos son transferidas a un computador portátil y son mostradas en la pantalla. A los participantes se les ofrece quedarse con copia de las fotos (impresas, en memorias USB o en Facebook). La conversación de cierre es grabada. La guía para la entrevista incluye preguntas tales como: ¿qué ves en esta foto? ¿Por qué la tomaste? ¿Cómo te hace sentir? (4) Análisis y diseminación: las grabaciones son transcritas, traducidas y codificadas para ser analizadas en Dedoose (software de análisis cualitativo). Ejemplos significativos de las entrevistas son seleccionados de los distintos temas que emergen del análisis y son editados por motivos de brevedad y para garantizar su claridad. Los nombres son cambiados (en el caso de la frontera entre México y EE. UU, las caras son sometidas a un proceso de edición digital que busca el anonimato de los participantes) para proteger la identidad de los participantes. Variaciones menores entre las distintas ubicaciones 
de la investigación incluyen la tecnología usada (cámaras prestadas por el equipo de investigación, cámaras propias, o fotos tomadas de las cuentas de Facebook o Flickr de los participantes) y la modalidad de participación (los participantes a menudo tomaban sus propias fotos; en Cali las fotos del contexto fueron ocasionalmente tomadas por el equipo de investigación en medio de la conversación con los participantes).

Fotohistorias se nutre de una larga tradición de investigación participativa, investigación visual (Collier, 1967), y en particular de fotografía participativa en el campo de las ciencias sociales, especialmente con migrantes (Frohmann, 2005; Kuok y Ku, 2008; Sutherland y Cheng, 2009; Rhodes et al., 2009; Holgate et al., 2012). La fotografía participativa aporta al menos tres elementos importantes a nuestra investigación: (1) empoderamiento: los participantes eligen sobre qué quieren hablar y pueden compartir y reflexionar sobre sus propias experiencias. Con frecuencia reportan sentirse empoderados, valorados y escuchados y con un sentido de agencia más fuerte. El proceso participativo transforma la dinámica de poder del entrevistador como la figura dominante, construye empatía y promueve un ambiente más seguro para que los participantes hablen sobre sus experiencias (Young y Barrett, 2001). (2) Multiplicidad de perspectivas: las fotos ayudan a cambiar las nociones preconcebidas de las preguntas y respuestas de tanto el participante como el entrevistado (Bignante, 2010). Hay múltiples perspectivas que pueden ser evocadas por una imagen, lo cual ayuda a facilitar una conversación que puede llevar a una exploración más profunda de emociones, valores y creencias. (3) Comprensión más rica: al hablar sobre las fotos (en vez de, por ejemplo, sus miedos o emociones), los participantes pueden externalizar emociones e ideas complejas más fácilmente. De esta manera, el poder de la imagen y de la historia, puestas en conjunto, ayudan a dar una comprensión más rica de un fenómeno que si se tomara la foto o la entrevista de manera independiente.

\section{Contextos diferentes para entender las prácticas de información en relación a la migración}

Para entender mejor las prácticas de información de los migrantes indocumentados, exploramos las experiencias de migración de los latinos en tres contextos diferentes: en la frontera entre México y EE. UU, en un centro de despacho de trabajo para jornaleros en Seattle, Washington y en comunidades marginales en Cali, Colombia. Tomadas como un todo, estos tres contextos para el trabajo de campo nos ofrecen un caleidoscopio de experiencias que le aportan textura y sustancia a las prácticas de información de los migrantes indocumentados y marginalizados en distintos momentos de la experiencia migratoria. Este artículo presenta los resultados en Colombia, mientras que un artículo aparte presenta los resultados en la frontera y en Seattle (Gómez, 2016). 
El caso colombiano se diferencia de los otros contextos para este estudio de varias maneras. Primero que todo, en Colombia encontramos potenciales transmigrantes, y personas que habían transmigrado en el pasado. Ellos representan o la fuente -de donde salen los transmigrantes- o el destino -adonde retornan-. Esta perspectiva es especialmente notoria en Bahía Málaga, una población cercana a Buenaventura, el puerto colombiano sobre el Océano Pacífico. La zona portuaria ha sido históricamente el punto de partida para polizones rumbo a EE. UU. Sin embargo, recientemente la migración se ha volcado internamente hacia Cali, la ciudad industrial más cercana, o internacionalmente hacia el Sur, hacia Perú y Chile, o en un movimiento migratorio por parte de quienes fueron migrantes (internos) y transmigrantes (internacionales) y ahora están regresando a la región.

Segundo, encontramos migrantes internos en Colombia. Estos representan migrantes dentro de un país, no transmigrantes. Sin salir del país, se han movido de una comunidad o ubicación geográfica a otra, ya sea para escapar de la violencia o para buscar mejores oportunidades de empleo y educación en la ciudad. Esta perspectiva es especialmente notoria en Buenavista, Cali (un asentamiento muy reciente, que en 2010 reunió a miembros de la comunidad indígena Nasa que habían dejado sus territorios ancestrales en la región del Cauca, al sur de Cali), y en Siloé, también en la periferia de Cali (Siloé fue poblada principalmente en las décadas de 1960 y 70, como parte de las olas de migración interna del campo a la ciudad). La pobreza y la ausencia de oportunidades económicas, combinadas con cinco décadas de violencia política en el país han causado enormes flujos migratorios, incluyendo, a la fecha, casi seis millones de personas desplazadas internamente (UNHCR, 2015). ${ }^{1}$

Un tercer tipo de experiencia la encontramos en Colombia en aquellos que tienen un vínculo profundo en su territorio y no quieren migrar. Las experiencias de estos no migrantes representan a aquellos que quieren quedarse en su lugar de origen, que no quieren migrar, y que prefieren ahondar sus raíces en un sitio y construir un futuro mejor donde se encuentran actualmente. A veces viven en su lugar de origen, en los lugares en los que sus antepasados llevan viviendo por varias generaciones (como en el caso de Bahía Málaga, donde la población afro colombiana se asentó hace más de 400 años), o bien llevan ahí sólo una generación o unos pocos años (como en el caso de Siloé, que fue poblada en la década de los sesenta, o Buenavista, poblada, en su mayoría, por miembros de la comunidad indígena Nasa que fueron desplazados hace unos años). Los no migrantes nos ofrecen una perspectiva única en el espectro de las experiencias de la migración: ya sea como nativos (nacidos ahí) o como recién llegados, están cons-

1. De una población total de alrededor de 40 millones de personas, además de estos 6 millones desplazados internamente por el conflicto, 4 millones residen permanentemente en el extranjero. De estos, una cuarta parte (1,2 millones), se fue después del año 2000, de acuerdo con estadísticas oficiales (DANE, 2015). 
truyendo un futuro ahí, y buscan mejorar las condiciones de vida en su comunidad para que los demás no se vayan, se quieran quedar, y vivan vidas prósperas y fructíferas «en su territorio». Para entender las prácticas de información de los migrantes, es necesario tener en cuenta, también, las vivencias de quienes no quieren migrar.

\section{Resultados: Prácticas de información para quedarse o para irse}

En la región de Cali y sus alrededores, encontramos migrantes internos que han sido desplazados por el conflicto o por la búsqueda de oportunidades económicas. Encontramos también a futuros migrantes o a migrantes regresando de EE. UU, Europa u otros países de Suramérica. Finalmente, encontramos a los no migrantes, aquellos que se quieren quedar en su territorio y construir, ahí, un futuro mejor para sí mismos y sus familias, sin migrar. Estas experiencias demuestran cómo la fase pre-migratoria es mucho más compleja que lo que sugieren Caidi y sus colegas (Caidi et al., 2010).

Cali es la tercera ciudad más grande de Colombia, y está conectada al resto del mundo a través del puerto marítimo de Buenaventura. Aproximadamente el $25 \%$ de la población de Cali es negra o afrocolombiana, con el resto de la población identificándose a sí misma como «no perteneciente a ninguna etnia», entendiéndose esto como blanco o mestizo. En Buenaventura, la población afrocolombiana es la mayoría, aproximadamente el 90\%. El departamento del Valle del Cauca ubicado al suroccidente de Colombia es principalmente rural y cuya ciudad principal es Cali, tiene más de un $20 \%$ de población indígena, la mayoría pertenecientes a la comunidad Nasa (también conocidos como Paeces). Las tres comunidades donde llevamos a cabo nuestro estudio Fotohistorias incluyeron población blanca o mestiza (Siloé), indígena (Buenavista) y afrocolombiana (Bahía Málaga). Aunque no pretendemos que nuestro estudio sea una muestra representativa de la población, sí nos da una variedad de perspectivas y experiencias de la relación entre la información y la migración.

\section{Bahía Málaga: aislada y construyendo un mejor futuro}

Bahía Málaga es una comunidad remota, a la que sólo hay acceso por barco. Está ubicada al norte de Buenaventura, sobre el océano Pacífico. Su población es predominantemente afro descendiente, aunque hay varios grupos indígenas que habitan cerca. Es una de las regiones más biodiversas del planeta, de una indescriptible belleza natural, y una pobreza que quita el aliento. El pueblo principal de La Plata-Bahía Málaga tiene aproximadamente 50 familias que viven en palafitos, sin acueducto, y sólo con cuentan electricidad ocasionalmente, ya que dependen de una planta eléctrica de diesel. Porfirio, 
uno de nuestros participantes en Bahía Málaga, nos contó por qué ama este lugar: «Es cierto que aquí hay pobreza, pero también hay paz y belleza».

En Bahía Málaga, la población está organizada bajo un Consejo Comunitario que tiene un título colectivo de tierras que incluye más de 47.00o hectáreas a su cargo. Administran una reserva natural y un parque marítimo del cual esperan que les provea, a través del ecoturismo y créditos de carbono, los recursos económicos que necesitan para mejorar las condiciones de vida de la comunidad. Hay una escuela con dos salones que ocasionalmente cuenta con profesores que dictan hasta cuarto de primaria. Luego de esto, los estudiantes tendrían que ir hasta Buenaventura para continuar con su educación. Mejorar la escuela es una de dos prioridades, de acuerdo con el líder comunitario Hoovert: ${ }^{2}$

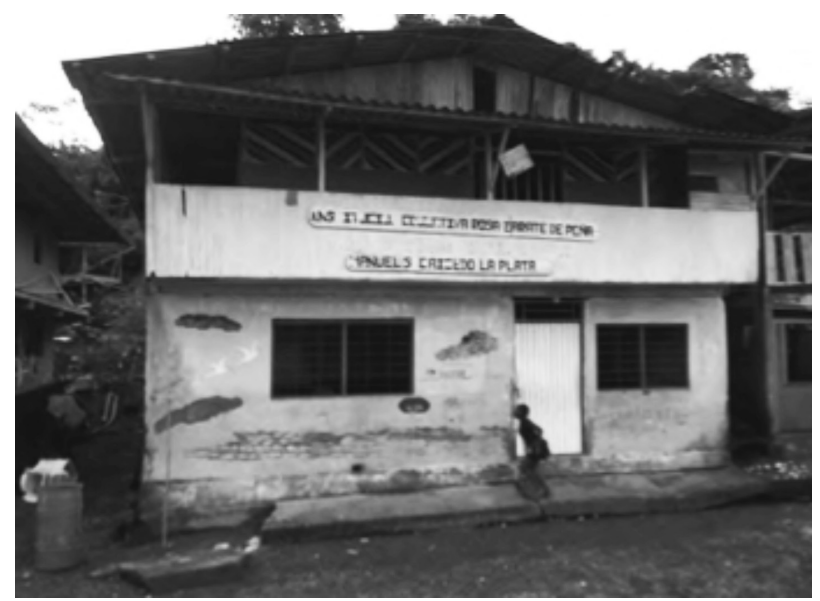

Hoovert: La escuela aqui neceista mejorar. Ese malagueño que quiere crecer y evolucionar educativamente, no ve allílas oportunidadespara hacerlo, nipara fijarse al territorio, entonces los busca por fuera.

El Consejo Comunitario publicita a Bahía Málaga en Facebook y en una página web, como un destino de ecoturismo. El pueblo tiene un «Punto Digital», un centro administrado por el gobierno y que cuenta con acceso a internet intermitente. Es usado principalmente por niños para acceder a Facebook y descargar música. La mayoría de la organización comunitaria y socialización de información es cara a cara: tiene lugar en reuniones formales, como en la cual discutieron nuestro proyecto y si deberían o no participar, y en reuniones informales, como las que se dan durante partidas de dominó:

2. Todas las entrevistas han sido editadas para garantizar su brevedad y claridad. 

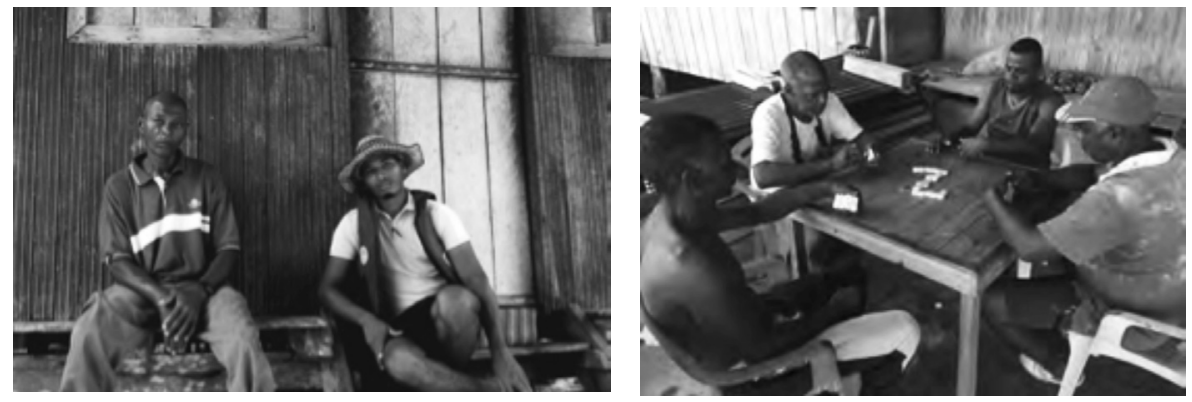

Ferney: La escuela, la formación de líderesy el relevo generacional, esa escala entre el mayor y el joven, encaja porque uno de los líderes mayores del territorio le enseñó al jóven y éste ha escuchadoy aprendido y hoy es el presidente del consejo comunitario.

Están anclados en el pasado, en su sentido de pertenencia a un territorio ancestral, y están enfocados en el futuro, en construir un lugar digno para las generaciones futuras.

Hoovert: Lo que caracteriza a la Plata, Bahía Málaga como territorio ancestral de comunidad negra es que inicialmente la población se asentó desde 1624 principalmente en las islase islotes. Y esta comunidad es una expresión de la expansión y la apropiación territorial de esa comunidad negra principalmente insular y luego continental con el pensamiento de mejorar las condiciones de vida.

La gente está más concentrada en cómo se construye ese futuro que le permita sostenerse y sostener las futuras generaciones para que mantenga el territorio, porque el territorio es el lugar por donde transita el pensamiento, de los viejos, de los niños, eso es fundamental. Otros principios y derechos fundamentales de nuestra comunidad son: autonomía, territorio, participación, visión propia de desarrollo y autodeterminación. Con estos elementos y toda la gestión como organización para mejorar el bienestar colectivo, se puede lograr la permanencia en el territorio, como también garantizar ese relevo de generación, para que nuestros hijos les puedan decir a nuestros nietos «aquí vivió mi abuelo, cultivó esto, sacó esto y todavía está».

En las precarias condiciones económicas de Bahía Málaga, los participantes no están ni cerca de la transitoriedad y vulnerabilidad de la frontera. Están en casa. Aunque hay pobreza, «hay tranquilidady belleza». La comunidad vive en un híbrido entre la pobreza de información del «pequeño mundo» en su cotidianidad, desconectados del resto del país, dada la ausencia de infraestructura y servicios, y la riqueza de información de un proyecto colectivo decidido a crear un mejor futuro en su territorio, conectado con la naturaleza y con el mundo a través de una reserva natural, la venta de créditos de carbono y proyectos eco turísticos. En su mayoría, la gente de Bahía Málaga está 
por fuera del espectro migratorio sugerido por Caidi y sus colegas (2010), porque son o «no migrantes» o «posmigrantes». Ellos ya han regresado a casa, o ya están en casa y no quieren partir.

\section{Buenavista: echando nuevas raíces en la ciudad}

Buenavista es un barrio ubicado en la periferia de Cali en el cual habitan aproximadamente 6oo personas, en su mayoría indígenas Nasa que dejaron su territorio ancestral, fueron desperdigadas alrededor de la ciudad, y en el 2005 decidieron reunirse en esta árida colina que da contra la ciudad. Ocuparon la tierra y construyeron chozas de bambú con techos de láminas de plástico. Lentamente han agregado paredes de ladrillo, techos de zinc y escalones de concreto para bajar a Cali a trabajar. Operan como una rama del Consejo Indígena Nasa, en este, su nuevo hogar urbano. Están tratando de restablecer y mantener sus raíces indígenas mientras viven en la ciudad. Aunque fue la tierra de sus ancestros antes de la llegada de los españoles, hoy en día no tienen títulos sobre las tierras que ocupan. Yolima nos cuenta sobre cómo su vida aquí es muy distinta de cómo era en su comunidad rural, donde el compartir los productos agrícolas garantizaba que a nadie le faltara alimento:

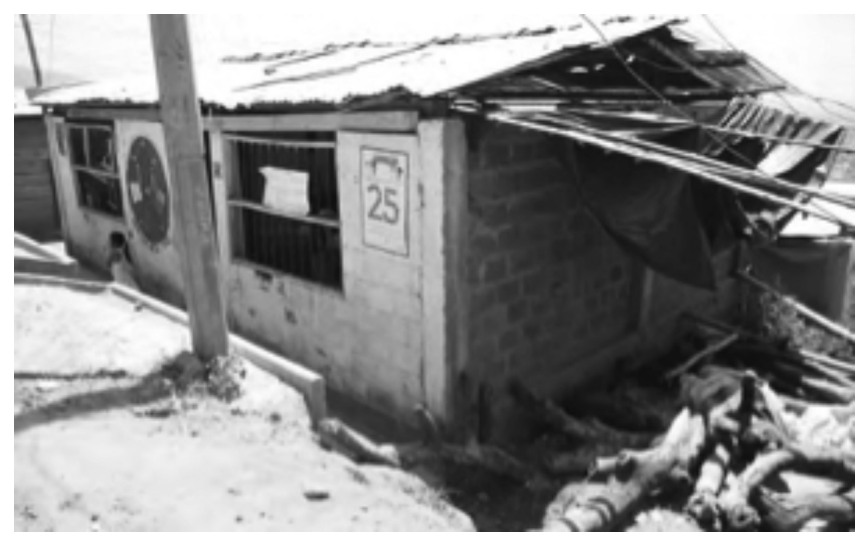

Foto de la casa del Cabildo Indígena en Buenavista, tomada por solicitud de Yolima (foto: S. Vannini)

Yolima: En comunidad, así es como se reúne en el cabildo, pueden ser 200, 300 personas, va uno al lugar, al territorio que tiene uno propio del cabildo y se trabaja, y se siembra los cultivos que sea, y la misma cantidad se va a cosechar, y se trae a la casa del cabildo, y de ahíy a se reparte para el mercadito de lo que es para la quincena, y el resto se vende, y esa plata para ir sacando adelante. 
Aunque la comunidad se estableció en Buenavista hace apenas 10 años, están trabajando para crear un lugar para sí mismos y sus familias que les permita vivir una vida productiva y con sentido. Otro de los participantes, Marco Antonio, tiene como actividad económica recoger basura para vender los productos reciclables, actividad de la que está muy orgulloso. Nos muestra su costal con los productos reciclables recogidos durante el día y nos cuenta sobre la felicidad que estos le traen:

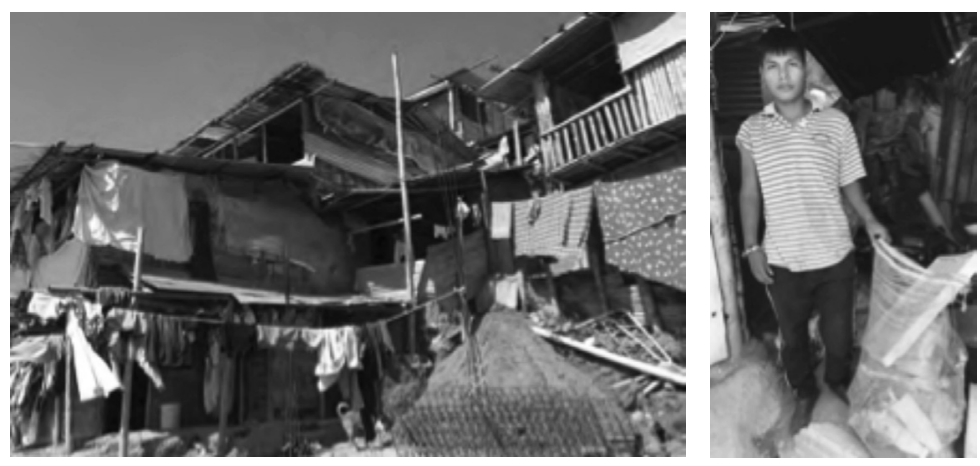

Fotos de Marco Antonio y su casa, a solicitud del mismo

(foto: R. Gomez)

Marco Antonio: Gran parte de mi comunidad vive de eso, del reciclaje. Aquílos quenotienen empleo, jóvenes, jovencitas, hombre, mujer o mayores, salen en las mañanas, ellos tienen días especiales en los que salen a reciclar. Esto es un ingreso más para el sustento de la casa, esta es la otra entrada de ellos. Me siento feliz porque séque tengo algo para vender. Cuando necesito dinero séque al reciclar tengo algo quévender.

A Juan Carlos lo eligieron recientemente Gobernador (líder del Consejo Indígena) de Buenavista, y se toma muy en serio su rol. Su hijo de tres años lo acompaña casi siempre, y Juan Carlos lleva orgullosamente su bastón de mando, símbolo de su autoridad, mientras recorre la colina hablando con los miembros de su comunidad. Insiste en que aunque ellos son Nasa, todos son bienvenidos en la sede del Consejo.
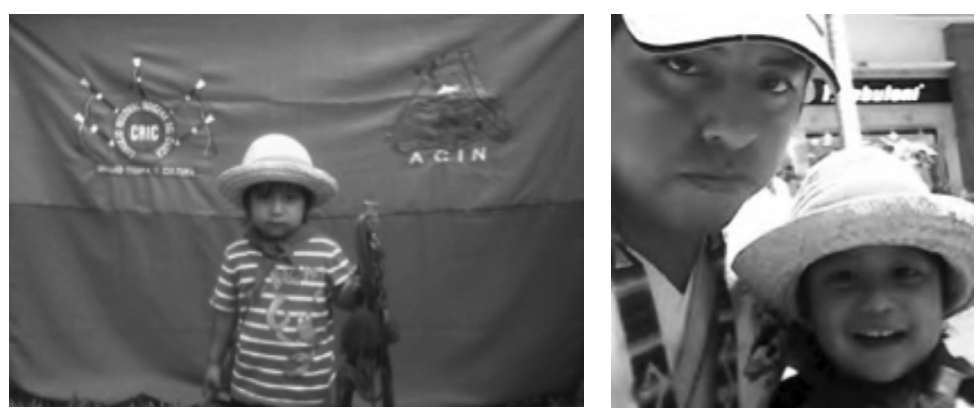
Juan Carlos: Es que al principio, como yo le decía, yo no entendía nada de esto, yo no sabía que era un indígena. Hoy en día yo entiendo todo esto, y lo que yo entiendo es lo que le estoy enseñando a mi hijo. Y mi hijo ya lo entiende, lo capta muy bien a pesar que tiene 3 años, él tiene una memoria muy avanzada y entiende muy bien esto.

Este movimiento indígena no es sólo para los indígenas, es para todos los sectores, como el afro, campesinos, mestizos, colonos. Porque igual todos somos indigenas, que hoy tengamos un color diferente o unos ojos diferentes, no significa que seamos diferentes a los demás. Todos somosiguales, todos fuimos mezclados en el tiempo de la conquista, ninguno somos originales, ni siquiera nosotros los indígenas. Fuimos mezclados con los afros, blancos, entre los mismos indígenas, por ello todos somos indígenas y la casa es de todos.

Vimos muchas antenas receptoras de señal satelital de televisión en Buenavista y todos los miembros de la comunidad con los que hablamos tenían un celular. Incluso Juan Carlos, el líder, tenía dos celulares. Nos explicó que tiene un celular básico con una tarjeta SIM pre pagada que puede recargar cuando sea necesario, y que le permite hacer y recibir llamadas. También tiene un teléfono inteligente que le regaló su novia, pero lo tiene sin plan de llamadas y sin plan de datos, porque es muy costoso. En realidad, sólo lo usa para tomar fotos, hacer grabaciones de audio y de video, y usar Facebook, Viber y Whatsapp. Juan Carlos es cuidadoso con su uso de los minutos, y prefiere frecuentar lugares que tienen acceso a internet inalámbrico gratuito para comunicarse usando redes sociales y para cargar fotos a su cuenta de Facebook. Está documentando la historia de su comunidad en su nuevo asentamiento en Buenavista a través de Facebook. Está creando su propia versión de Fotohistorias.

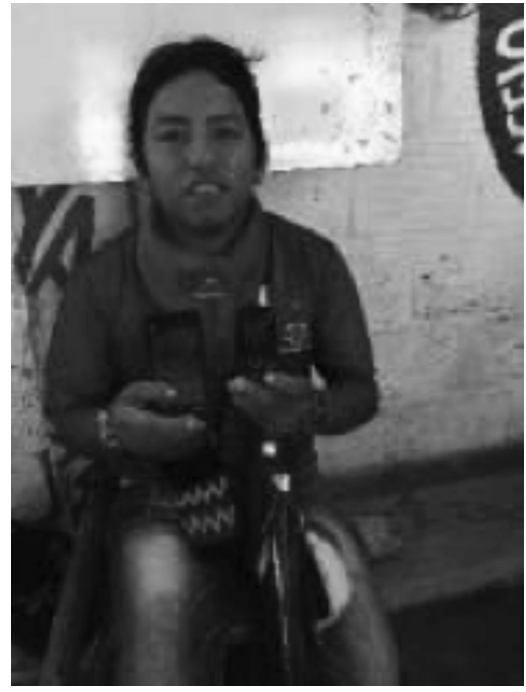

Juan Carlos muestra sus dos teléfonos, con y sin tarjeta SIM (foto: R. Gomez) 
Juan Carlos usa las tecnologías de información a las que tiene acceso de maneras creativas que le permiten satisfacer sus necesidades y las de su comunidad. Nos contó que recibió una llamada en la que le contaban que uno de los líderes estaba en el hospital y necesitaba protección. En vez de usar sus preciados minutos de llamadas para ver quién podría ir al hospital, prefirió pagar un transporte que lo llevara a un lugar con acceso a internet inalámbrico gratuito («plaza wi-fi»), como la terminal de bus, el centro comercial o la biblioteca pública, y usó redes sociales para pedir ayuda. En la hora siguiente había alguien acompañando al líder en el hospital. El caso de Juan Carlos muestra las funciones de identidad TI de expresión, mantenimiento y expansión del ser. En términos de la expresión del ser, el uso que le da a las TI está estrechamente relacionado con su cargo como Gobernador de Buenavista, una persona que debe tener un papel central en la comunicación de las distintas redes, que está cargo de registrar la historia de su comunidad y que es responsable por la seguridad de la población de Buenavista. Documentar la historia comunal hace parte de su esfuerzo por mantener el ser y enfrentarse a los retos de identidad que le impone el entorno a la comunidad Nasa. Cómo se enfrentó con la emergencia de uno de los miembros de la comunidad ilustra cómo se sobrepuso a la brecha entre su sentido de responsabilidad como líder, y las limitaciones físicas y geográficas que le impedían cumplir con su rol; es entonces un ejemplo de cómo expandió su ser con su identidad TI (Carter y Grove, 2015).

La comunidad de Buenavista está rápidamente acomodándose en su nuevo barrio, y está poco a poco echando raíces que la conectan a su territorio ancestral. Como en el caso de los migrantes que entrevistamos en Seattle, los participantes de Buenavista son migrantes internos con trabajos precarios y sin ningún documento legal que los reconoce como propietarios de su tierra. Sus comportamientos de información expanden de manera creativa su red de relaciones con la ciudad a sus pies, con los vecinos no indígenas y con la comunidad indígena ancestral y étnica en sus lugares de origen. Como los migrantes latinos en Seattle, los habitantes indígenas de Buenavista, en la periferia de Cali, viven en un constante tránsito entre las etapas de migración inmediata, intermedia y de integración (Caidi et al., 2010), con prácticas de información que les ayudan a encontrar y mantener un techo, satisfacer sus necesidades básicas, acceder a servicios locales y buscar una participación en la arena pública más fuerte. Aunque no están indocumentados en la misma forma que los migrantes latinos en EE. UU, los habitantes de Buenavista son poseedores ilegales, indocumentados a su manera, sin títulos sobre su tierra y sin reconocimiento jurídico como grupo indígena ubicado al margen de una ciudad industrial.

\section{Siloé: Convirtiendo recuerdos en planes}

Siloé es un barrio de clase trabajadora caleña que inició en la década de los cincuenta de forma similar a como nació Buenavista: con migrantes internos huyendo de la violencia 
del campo y asentándose en la ciudad buscando más oportunidades de trabajo. En la década de los setenta, fue cuna de uno de los movimientos de guerrilla de izquierda en el país, el M-19, lo cual dejó un legado de organización política y un estigma de violencia que se vio reforzado por los carteles de droga en la década de los noventa. David es un líder comunitario dedicado a ayudar a Siloé, que ahora es una ciudad dentro de una ciudad, para que sea un sitio en el que sus habitantes puedan prosperar. Esto implica superar el estigma de violencia sin dejar de lado la memoria de su identidad cultural. Algunos de los elementos claves de esta estrategia incluyen un museo comunitario y una emisora de radio comunitaria:
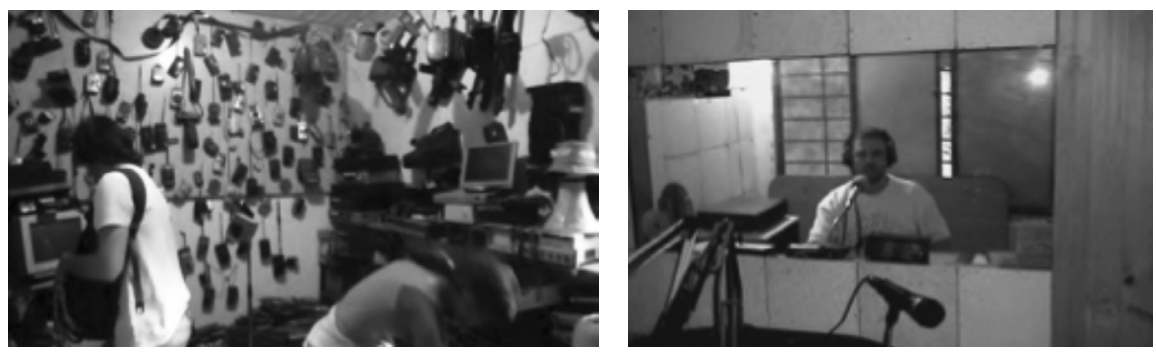

David: Queremosmantener la memoria histórica de nuestroterritorio. Unpueblosinmemoria histórica, no es un pueblo, no existe. Eso lo entendemos nosotros.

Es una buena pregunta, porque las cosas de nosotros las ven más la gente de afuera que la gente de adentro. Pero tenemos la emisora de la comunidad, que en este momento el transmisor está dañado, pero entonces esa es más local. Pero la gente de afuera sí ve más lo de acá adentro, yo no sé cómo medir eso pero son como dos mily pico de visitas diarias.

El Museo Popular de Siloé, fundado por David, busca contar la historia del barrio y de su gente. Invitan a los niños a que lo visiten y aprendan de la colección de objetos expuestos en dos salas: recortes de periódico, objetos de interés, testimonios. Nada está detrás de vidrios de protección. Todo está dispuesto para que pueda ser tocado y su historia contada. El transmisor de la emisora comunitaria estaba dañado cuando visitamos, pero el canal digital estaba más activo que nunca. Mientras que la información de boca en boca, de voz a voz, y las muestras interactivas fortalecen a la comunidad hacia adentro, conectándola con sus recuerdos y sus raíces, las tecnologías de información conectan a la comunidad hacia fuera, con el resto del mundo.

La educación no formal es una actividad importante para la organización sin ánimo de lucro SIDOC, en Siloé. En vez de entregar dinero o bienes, ofrecen oportunidades de capacitación. Como nos lo confiesa Jessica, hay personas que se sorprenden con esto: 


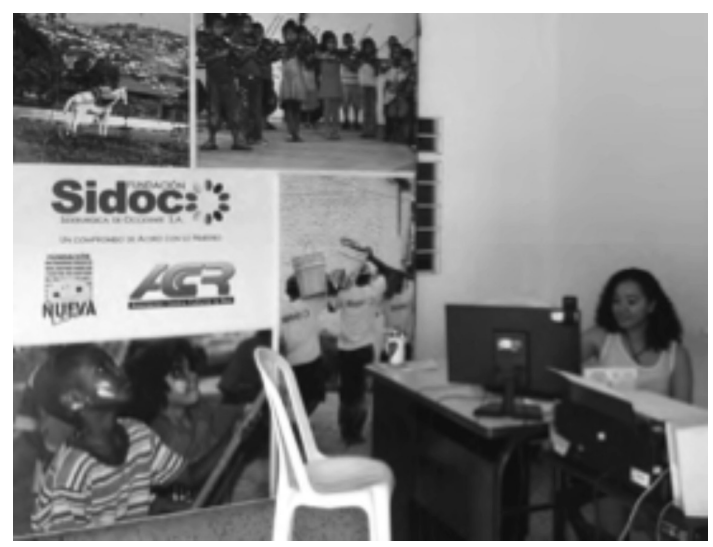

Jessica: En la cultura de la población vulnerable digamos como que se han estigmatizado un poco las labores que tienen que ver con fundacionesy lo piensan mucho: que son entidades del estado, se les va a brindar algo gratis o se les va a dar plata, o se les va a dar subsidios, o se les va a dar otras cosas. Cuando vienen acá y miran como que «hay capacitación,» como que me tengo que formar, tengo que hacer tareas, tengo que estudiar, es como que «mmm».

Otro lugar importante en Siloé es la biblioteca comunitaria, aunque David se lamenta de que los computadores instalados en la iniciativa estatal Punto Digital, están teniendo algunos efectos negativos en los niños:

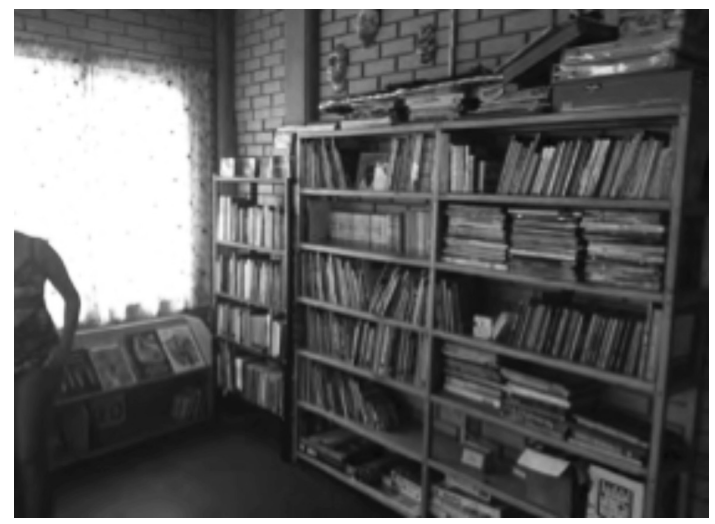

David: Entonces, el punto digital, el título es muy bonito y todo el cuento, pero eso lo que ha traído es que los niños no vengan a la biblioteca a consultar... La partieron para armar todo el punto digital. Como está el punto digitaly los computadores son portátiles, los deben asegurar, no pueden dejar mezclar los niños o los jóvenes, porque se pueden llevar, supuestamente, el computador. Están poniendo por encima la seguridad del aparato. 
Para David, los niños están perdiendo el interés con los libros, un recurso importante, desde la llegada de los computadores a la biblioteca. En vez de ser una ventana a un mundo más amplio, David se queja de que los computadores en el Punto Digital ni siquiera se están usando, porque están guardados bajo llave. Esta expresión híbrida del conflicto entre los computadores y los libros, «pequeño mundo» VS. el «gran mundo» es bastante única.

Finalmente, David también nos comparte fotos del metro cable en construcción, el cual transformará a la comunidad (tal y como el metro cable ha transformado a las comunidades marginadas en Medellín, Colombia):

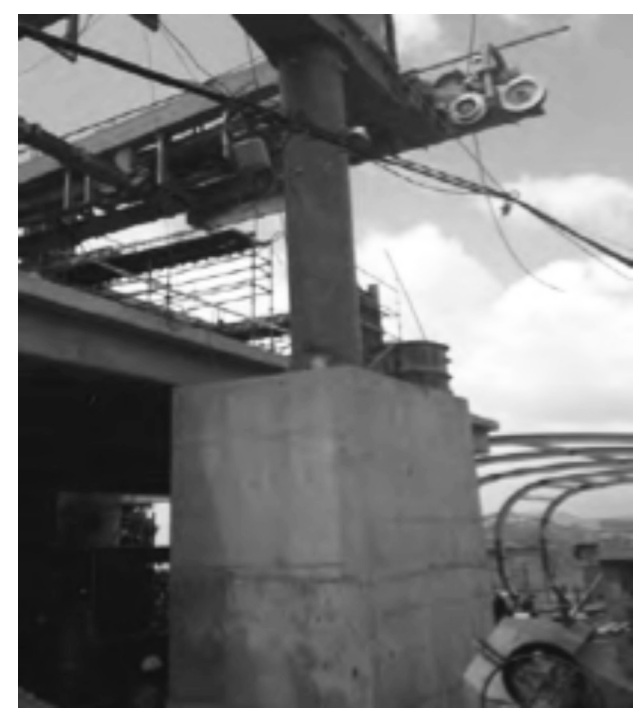

David: Elcable aéreo va a serun espacio de transporte de la gente de la ciudad, y la misma gente de aqui de la comunidad que va a subir acá. Se va a volver muy turístico, y es una obra física que va a terminar atrayendo la gente, extranjeros como tú que van caminando o que andan con nosotros acá, a lo mejor no van a tener la necesidad de caminar, sino que se montan allá, $y$ van a hacer turismo aéreo. O sea que hay much gente que nos va a mirar, eso va a obligar a la comunidad, a organizaciones comunitarias, y sobre todo el Estado y la empresa privada a que inviertan en el territorio, eso va a ser un mecanismo positivo, que nos tiene que poner a la palestra de la ciudad, va a cambiar el Siloé de hoy, después de que comience a funcionar, y la ciudad también.

David tiene esperanzas de un futuro mejor para Siloé y sus habitantes, un lugar que están construyendo y recordando juntos, un lugar en el que pueden quedarse y del cual se pueden sentir orgullosos. Los participantes en Siloé tienen prácticas de información 
que convergen con las etapas de migración intermedia y de integración (Caidi et al., 2010): una vez que logran satisfacer las necesidades básicas que garantizan su supervivencia, están enfocados en acceder y exigir servicios locales (vivienda, salud, empleo, recreación, transporte) y en construir espacios de participación ciudadana por medio de la biblioteca, la radio, parques, etc. Como la gente en Bahía Málaga, quieren crear un territorio en el que se sientan arraigados. En el Continuo de la Transitoriedad, sus experiencias están entre los extremos de transitoriedad y permanencia: moderadamente transitorios (Buenavista) o moderadamente duraderos (Siloé). Aun así, esta vida en el medio del continuo que exhiben los participantes en Colombia, no es como en el cuento de Ricitos de Oro, «en su punto». Están atascados entre la transitoriedad y la permanencia y viven vidas precarias de marginación, pobreza y exclusión. Hay esperanza, pero se necesita todavía mucho trabajo para que sus condiciones de vida estén «en su punto».

\section{Conclusiones: información para el pequeño y gran mundo}

Analizamos diferentes prácticas de información de migrantes en comunidades al sur de Colombia, que contrastan con las de migrantes en la frontera entre México y EE. UU, en Seattle (Gómez, 2016), evocadas a través de la fotografía participativa. Exploramos estas experiencias de la migración a través del lente del Continuo de la Transitoriedad (Vannini et al., 2016) y del continuo de la migración (Caidi et al., 2010) para entender mejor sus prácticas y comportamientos de información. Mostramos cómo las prácticas de información de migrantes en distintos contextos no siguen la progresión lineal de las etapas de migración (la etapa pre migratoria, la etapa inmediata, la etapa intermedia y la etapa de integración) que sugirieron Caidi y sus colegas (2010). En vez de esta linealidad, vemos que hay mayor probabilidad de que vivencien varias etapas al mismo tiempo, y que oscilen entre una y otra etapa en un contexto de migración. Más aún, las experiencias de los no migrantes (que no van a ningún lado) y las de los pos migrantes (los que están regresando) deben ser incluidas en el marco conceptual.

La noción del Continuo de la Transitoriedad requiere más desarrollo, aunque ayuda a entender el proceso cíclico e iterativo de los migrantes y sus implicaciones en sus prácticas de información: entre la cuidadosa búsqueda de información en fuentes confiables (en el extremo de la transitoriedad), y la socialización generosa de información con otros (en el extremo de la permanencia). Además, la noción de pobreza de información del «pequeño mundo» (Chatman, 1996), nos ayuda a entender mejor y a diferenciar las prácticas de información de quienes viven las batallas cotidianas por la sobrevivencia en comunidades marginadas en Colombia, y cómo contrastan con las prácticas de información de migrantes viviendo en las condiciones precarias de transitoriedad de la frontera, o en las condiciones precarias de vulnerabilidad e incertidumbre laboral de los jornaleros en Seattle. 
En las diferentes comunidades colombianas estudiadas, las prácticas de información se centran en la construcción de un futuro posible en el territorio, un lugar donde cultivar la identidad propia y el sentido de pertenencia, un lugar donde las personas se quieran quedar y no migrar a otra parte. Esto se manifiesta de maneras diferentes en la comunidad afro-descendiente de Bahía Málaga cerca del puerto de Buenaventura, en la comunidad indígena de Buenavista cerca de la capital regional de Cali, o en la comunidad obrera de segunda generación de migrantes en Siloé, en la periferia de Cali. En todas los habitantes se han establecido y buscan construir su territorio, echar raíces para que las generaciones futuras tengan una vida digna. Las prácticas de información más comunes son las que permiten negociar las dificultades de la vida cotidiana a la vez que se abren a las oportunidades amplias y diversas del mundo que les rodea.

Las vivencias de extrema transitoriedad y vulnerabilidad de los migrantes llevan a prácticas más restrictivas y más pobres de información que se enfocan en la supervivencia, mientras que vivencias más permanentes de migración, incluso si también están sometidos a la marginación y son vulnerables, pueden llevar a prácticas más ricas de información que se enfocan en la comunidad y en la participación ciudadana. Los teléfonos celulares y los computadores, las bibliotecas y las organizaciones que ofrecen servicios, todos contribuyen a enriquecer los mundos de información de los migrantes. Todos los migrantes, sin importar su origen, su condición actual, o sus planes para el futuro, están en constante movimiento, trabajando para construir un mundo mejor para sí mismos, sus familias y sus comunidades. Todos los migrantes tienen, como mínimo, el derecho a tener derechos, incluyendo el derecho a buscar, usar y compartir información para un mundo mejor.

\section{Referencias}

BIGNANTE, E. (2010). The use of photo-elicitation in field research. EchoGéo, no 11. Recuperado de: http://echogeo.revues.org/11622

CAIDI, N., Allard, D., \& Quirke, L. (2010). Information practices of immigrants. Annual Review of Information Science and Technology, 44(1), 491-531.

CARTER, M., \& Grover, V. (2015). Me, My Self, and I (T): Conceptualizing Information Technology Identity and its Implications. MIS Quarterly, 39(4), 931-957.

CHATMAN, E. A. (1996). The Impoverished Life-World of Outsiders. Journal of the American Society for Information Science, 47, 193-206.

COLLIER, J. (1967). Visual anthropology:photography as a research method. Holt, Rinehart and Winston. 
FISHER, K. E., \& Julien, H. (2009). Information behavior. Annual Review of Information Science and Technology, 43(1), 1-73.

FROHMANN, L. (2005). The Framing Safety Project Photographs and Narratives by Battered Women. Violence Against Women, 11(11), 1396-1419. Recuperado de:http://doi.org/10.1177/1077801205280271

GÓMEZ, R. (2016). Vulnerabilidad y prácticas de información: experiencias de migrantes latinos (indocumentados) en EE.UU. Revista CS, no.20, pp. 93-121. Cali, Colombia: Facultad de Derecho y Ciencias Sociales, Universidad Icesi.

GOMEZ, R., \& Vannini, S. (2015). Fotohistorias: Participatory Photography and the Experience of Migration. Charleston, SC: CreateSpace.

HOLGATE, J., Keles, J., \& Kumarappan, L. (2012). Visualizing «community»: an experiment in participatory photography among Kurdish diasporic workers in London. The Sociological Review, 6o(2), 312-332. http://doi.org/10.1111/j.1467-954X.2012.02075.x

KWOK, J. Y., \& Ku, H.-B. (2008). Making habitable space together with female Chinese immigrants to Hong Kong An interdisciplinary participatory action research project. Action Research, 6(3), 261-283. http://doi.org/10.1177/1476750308094131

NAIL, T. (2015). The Figure of the Migrant. Stanford, California: Stanford University Press.

RHODES, S. D., Hergenrather, K. C., Griffith, D. M., Yee, L. J., Zometa, C. S., Montaño, J., \& Vissman, A. T. (2009). Sexual and alcohol risk behaviours of immigrant Latino men in the South-eastern USA. Culture, Health \& Sexuality, 11(1), 17-34. Recuperado de: http://doi.org/10.1080/13691050802488405

SAVOLAINEN, R. (2008). Everyday information practices: a social phenomenological perspective. Scarecrow Press.

SUTHERLAND, C., \& Cheng, Y. (2009). Participatory-Action Research with (Im)migrant Women in Two Small Canadian Cities: Using Photovoice in Kingston and Peterborough, Ontario. Journal of Immigrant \& Refugee Studies, 7(3), 290-307. Recuperado de: http://doi.org/10.1080/15562940903150089

UNHCR. (2015). UNHCR-Colombia. Recuperado de: http://www.unhcr.org/pages/49e492ad6.html

VANNINI, S., Gomez, R., \& Guajardo, V. (2016). Security and Activism: Using participatory photography to elicit perceptions of Information and Authority among Hispanic migrants in the U.S. In Proceedings of iConference 2016. Philadelphia, PA.

YEFIMOVA, K., Neils, M., Newell, B. C., \& Gomez, R. (2015). Fotohistorias: Participatory Photography as a Methodology to Elicit the Life Experiences of Migrants. In Proceedings of HICSS 48 . Hawaii. Recuperado de: http://papers.ssrn.com/abstract $=2482520$

YOUNG, L., \& Barrett, H. (2001). Adapting visual methods: action research with Kampala street children. Area, 33(2), 141-152. http://doi.org/10.1111/1475-4762.00017 